\title{
Çocuklarda primer böbrek tümörlerinin klinik özellikleri, tedavi yaklaşımları ve tedavi sonuçları
}

\section{The clinical features, treatment approaches and outcomes of primary renal tumors in children}

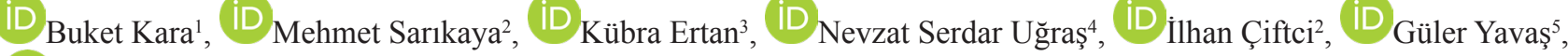
iD Yavuz Köksal ${ }^{1}$

\author{
${ }^{1}$ Department of Pediatric Hematology and Oncology, Selcuk University, Faculty of Medicine, Konya, Turkey. \\ ${ }^{2}$ Department of Pediatric Surgery, Selcuk University, Faculty of Medicine, Konya, Turkey \\ ${ }^{3}$ Department of Pediatrics, Selcuk University, Faculty of Medicine, Konya, Turkey \\ ${ }^{4}$ Department of Pathology, Selcuk University, Faculty of Medicine, Konya, Turkey \\ ${ }^{2}$ Department of Pediatric Surgery, Selcuk University, Faculty of Medicine, Konya, Turkey \\ ${ }^{5}$ Department of Radiation Oncology, Selcuk University, Faculty of Medicine, Konya, Turkey
}

$\ddot{\mathbf{O z}}$

Amaç: Bu çalışmanın amacı, çocuklarda primer malign böbrek tümörlerinin klinik özellikleri, tedavi yaklaşımları ve tedavi sonuçlarının değerlendirilmesidir.

Gereç ve Yöntem: 2006 ile 2020 yılları arasında primer malign böbrek tümör tanısı alan ve izlenen çocuk hastaların onkoloji dosyaları geriye yönelik incelendi. Hastaların demografik ve klinik özellikleri ile tedavi yaklașımları ve izlemleri not edildi.

Bulgular: Bu yıllar arasında izlenen 950 malign hastalıklı çocuğun 49'unda(\%5,2) primer malign böbrek tümörü vardı. Hastaların yaşı üç gün ile 13 yıl arasında değişiyordu (ortanca, 3 yıl). Erkek kız oranı 25/24'dü. En sık görülen semptom ve bulgu karında kitle idi. İki hastada bilateral hastalık vardı (\%4,1). Patolojik tanılar, Wilms tümörü (n= 44, \% 89,8), mezoblastik nefroma ( $\mathrm{n}=2, \% 4,1)$, böbreğin clear hücreli sarkomu ( $\mathrm{n}=2, \% 4,1)$ ve böbreğin primer sinovyal sarkomuydu ( $\mathrm{n}=1, \% 2)$. Wilms tümörlü hastalardan sadece ikinde diffüz anaplazi vardı. Hastalarımızın risk grupları düşük $(n=4, \% 8.3)$, orta $(n=35, \% 72.9)$ ve yüksek riskli (n=9, \% 18.8) idi. Hastaların takip süreleri iki ay ile 15 yıl (ortanca, 5 yıl) arasında değişiyordu. Primer böbrek tümörlerinde genel ve olaysız sağ kalım oranları sırasıyla \% 72,7 ve\% 59,7 idi. Wilms tümörlü hastaların genel ve olaysız sağ kalım oranları $\% 79$ ve $\% 63$ 'dü.

Sonuç: Primer malign böbrek tümörlerinde özellikle de Wilms tümöründe multidisipliner yaklaşımlarla başarı oranları yükselmiştir. Bundan sonra hem tedavi başarısının daha da artırılması hem de tedavi ilişkili yan etkilerin azaltılması üzerinde durulmalıdır.

Anahtar kelimeler: Çocuk, primer malign böbrek tümörleri, tedavi yaklaşımları, tedavi sonuçları

Abstract

Objective: The aim of this study is to evaluate the clinical features, treatment approaches and outcomes of primary malign renal tumors in children.

Material and Methods: The oncology charts of children diagnosed and followed up with primary malign renal tumors between 2006 and 2020 were retrospectively analyzed. Demographic and clinical characteristics, treatment approaches and follow-up of the patients were noted.

Results: In this period, 49 of 950 children with malignant disease had primary renal kidney tumors (5.2\%). The patients' age ranged from three days to 13 years (median, 3 years). The male to female ratio was $25 / 24$. The most common symptom and signs were abdominal mass. Both patients had bilateral disease (4.1\%). Pathological diagnoses were Wilms tumor $(\mathrm{n}=44,89.8 \%)$, mesoblastic nephroma $(\mathrm{n}=2,4.1 \%)$, clear cell sarcoma of the kidney $(\mathrm{n}=2,4.1 \%)$, and primary synovial sarcoma of the kidney $(\mathrm{n}=1$, $2 \%)$. Only two of the patients with Wilms tumor had diffuse anaplasia. The risk groups of our patients were low $(\mathrm{n}=4,8.3 \%)$, intermediate $(\mathrm{n}=35,72.9 \%)$ and high risk $(\mathrm{n}=9$, $18.8 \%$ ). Follow-up periods ranged from two months to 15 years (median, 5 years). Overall and event free survival rates were $72.7 \%$ and $59.7 \%$, respectively. Overall and event-free survival rates of Wilms tumor were $79 \%$ and $63 \%$.

Conclusion: Multidisciplinary approaches have increased success rates in primary malignant kidney tumors, especially in Wilms tumor. After that, it should be focused on both increasing the success of the treatment and reducing the treatment-related side effects.

Key Words: Children, primary renal tumors, treatment approaches, outcome

Yazışma Adresi: Buket Kara, Department of Pediatric Hematology and Oncology, Selcuk University, Faculty of Medicine, Konya, Turkey.

E-Posta: buketkara1001@gmail.com

Alınma tarihi: 10.03.2021 / Kabul tarihi: 13.04.2021 / Yayımlanma tarihi: 15.12.2021

Çocuklarda primer böbrek tümörü - Kara ve ark.

Genel Tip Derg 2021;31(4)375-379 


\section{Giriş}

Dünyada, çocukluk çağı primer böbrek tümörleri, tüm çocukluk çağı tümörlerinin yaklaşık olarak \%6'sını oluşturmaktadır. Ülkemizde ise, Türkiye Ulusal Pediatrik Kanser Kayıtlarına göre bu oran \%5,6 iken hastane tabanlı çocukluk çağı kanser kayıtlarında oran \%9,2 olarak raporlanmıştır $(1,2)$. Hastaların önemli bir kısmının yaşamın ilk beş yılı içinde tanı aldığı iyi bilinmektedir (3). Yetişkin yaş grubunda böbreğin karsinomları ön planda iken çocuk yaş grubunda primer tümörlerin çok büyük kısmını bir embriyonik tümör olan Wilms tümörü oluşturmaktadır. Çocukluk yaş grubunda, Wilms tümörü dışında böbrekte görülen tümörler; renal hücreli karsinom, böbreğin clear hücreli karsinomu, yine böbreğin malign rabdoid tümörü, konjenital mezoblastik nefroma, primitif neuroektodermal tümörü, böbreğin primer lenfoması ve böbreğin primer sinovyal sarkomu daha nadir görülmektedir (3-5).

Çocukluk çağının en sık primer böbrek tümörü olan Wilms tümörünün konjenital malformasyonlar ile birlikteliği, özellikle bu tümörlerde $W T 1$ ve $W T 2$ genlerinin tanımlanması ile onkogenler konusunda bize oldukça yol göstermiştir. Wilms tümörünün bir başka önemli özelliği genitoüriner malformasyonlar, aniridi, hemihipertrofi gibi konjenital malformasyonlar veya Denys Drash sendromu, Beckwith Wiedamann sendromu ya da WAGR sendromu gibi genetik sendromlar ile birlikteliğidir ve bu Wilms tümörlü hastaların yaklaşık \%7'sinde görülmektedir (6). Wilms tümörünün bir başka önemli özelliği de multimodal tedavi yaklaşımları ile oldukça yüz güldürücü tedavi sonuçlarının elde edilmesidir (3).

Burada, kliniğimizde tanı alan ve takip edilen primer malign böbrek tümörlü çocukların demografik ve klinik özellikleri, tedavi yaklaşımları ve sonuçları değerlendirilecektir.

\section{Gereç ve Yöntem}

$\mathrm{Bu}$ çalışma için, Selçuk Üniversitesi, Tıp Fakültesi, Yerel Etik Kurulundan 24.02.2021 2021/89 numarası ile izin alındıktan sonra Helsinki Bildirgesi ilkeleri çerçevesinde yapılmıştır. Retrospektif bir çalışma olduğu için hasta ya da hasta yakınlarından onam alınmamıştır.

Bu çalışmada, kliniğimizde 2006 y1lı ile 2020 yılları arasında tanı almış ve takip edilen, primer malign böbrek tümörlü çocuk hastaların dosyaları geriye dönük olarak incelendi. Hastaların pediatrik onkoloji dosyalarından, yaş, cinsiyet, başvuru anındaki yakınmaları ve fizik muayene bulguları (varsa konjenital malformasyon ya da sendromları da not edildi), diğer klinik bulguları ile patolojik bulguları not edildi. Evrelendirme Türk Pediatrik Onkoloji Grubu'nun TPOG-Wilms tümör protokolüne göre yapıldı (7).

Patolojik incelemesine göre hastalar, International Society of Paediatric Oncology (SIOP)'un patolojik sınıflandırması esas alınarak şu şekilde sınıflandırıldı (8):

1. İyi histoloji grubu

2. Kötü histoloji grubu (yaygın anaplazi varlığı, preoperatif kemoterapi sonrasında blastemal tip, böbreğin clear hücreli tümörü dahil edildi.)

Hastaların tedavi yaklaşımlarında 2006 ile 2015 yılları arasında TPOG-Wilms tümörü protokolüne göre, daha sonraki yıllarda preoperatif kemoterapi alan hastalarda SIOP 93-01, primer cerrahi tedavi uygulanan hastalarda ise National Wilms' Tumor Study Group'un (NWTS) tedavi protokolü kullanıldı $(9,10)$.

İstatistiksel analiz için IBM Statistical Package for Social Sciences (SPSS) versiyon 21 yazılım programı kullanıldı. Tanımlayıcı istatistik olarak:

1. Kategorik veriler için frekans ve yüzde değerleri

2. Numerik veriler için, veri dağılımı normal ise aritmetik ortalama ve standart sapma ile beraber, veri dağılımı normal değilse ortanca değer en küçük ve en büyük değer ile beraber verildi.

Kategorik verilerin karşılaştırılmasında $\chi^{2}$ testleri, numerik verilerin karşılaştırılmasında ise student $T$ testi ya da Mann Whitney $U$ testi kullanıldı. Sağ kalım analizleri Kaplan - Meier yöntemi kullanılarak yapılmıştır. Genel sağ kalım ve olaysız sağ kalım oranlarındaki farklılıkları karşılaştırmak için log-rank testi kullanıldı. Alfa değeri (p) 0.05 'ten küçük ise istatistiksel olarak anlamlı kabul edildi.

\section{Bulgular}

Kliniğimizde, 2006 ile 2020 yılları arasında 950 malign hastalığı olan hasta izlendi. Bunlardan 49'u primer malign böbrek tümörlü çocuk hastaydı (\%5,2). Erkek/kız oranı 25/24 idi. Hastaların yaşları üç gün ile 13 yıl arasında değişiyordu (ortanca, 3 yıl). Yaşların dağılımı Resim 1'de görülmektedir. Hiçbir hastamızda, ailesel böbrek tümörü öyküsü yoktu. Başvuru anındaki yakınma ve fizik muayene bulguları ile klinik özellikleri Tablo 1'de görülmektedir. En sık başvuru şikâyeti karında şişlik $(\mathrm{n}=27, \% 55,1)$ ve karın ağrısı $(\mathrm{n}=16, \% 32,7)$ iken, başvuru anında en sık saptanan fizik muayene bulgusu karında kitle ( $\mathrm{n}=49, \% 100)$ idi. Bir hastada WAGR ve bir hastada ise BeckwithWiedemann sendromu vard1.

Yirmi yedi hastaya $(\% 55,1)$ primer olarak cerrahi tedavi uygulanırken, 22 hastaya preoperatif kemoterapi tedavisi uyguland. Altı hastada, vena kava inferiorda tümör trombüsü nedeniyle ve diğer 16 hastada kitle büyüklüğü nedeniyle preoperatif kemoterapi uygulandı.

Patolojik incelemede sırasıyla Wilms tümörü (n: 44, \%89,8), mezoblastik nefroma (n: 2, \%4,1), berrak hücreli karsinom(n: 2, \% 4,1 ), ve böbreğin primer sinovyal sarkomu tanıları konulmuştu (n: 1, \%) (Tablo 2). SIOP risk sinıflandırmasına göre hastalar $\mathrm{n}$ sık orta risk grubunda yer almaktayd $1(\mathrm{n}=35, \% 79,5)$. Wilms tümörlü hastalarında en çok evre 3 saptandı (n:20, \%40,8).

\section{Yaşam analizleri}

Primer böbrek tümörlü hastaların genel yaşam analizleri değerlendirildiğinde, genel ve olaysız yaşam oranları, sırasıyla \% 72,7 ve \% 59,7 idi (Resim 2 ve 3). Wilms tümörleri dahil edildiğinde bu oranlar $\% 79$ ve $\% 63$ 'dü. Hastaların izlem süreleri iki ay ile 15 yıl arasında değişiyordu (ortanca, 5 yıl). Genel yaşam analizleri üzerine etki eden faktörler incelendiğinde, cinsiyetin, ilk tedavi yaklaşımın, evre, hastalık yaygınlığının, anaplazi varlığının, SIOP'a göre risk sınıflandırmasının etki etmediği görüldü (Tablo 3). 
Tablo 1: Hastaların başvuru şikayet ve bulguları

\begin{tabular}{|c|c|c|}
\hline & $\mathrm{n}$ & $\%$ \\
\hline \multicolumn{3}{|l|}{ Yakınma } \\
\hline Karında şişlik & 27 & 55,1 \\
\hline Karın ağrısı & 16 & 32,7 \\
\hline Hematüri & 9 & 18,4 \\
\hline Ateş & 7 & 14,3 \\
\hline Rutin kontrol & 6 & 12,2 \\
\hline Prenatal tanı & 2 & 4,1 \\
\hline \multicolumn{3}{|l|}{ Bulgu } \\
\hline Kitle & 49 & 100 \\
\hline Ateş & 7 & 14,3 \\
\hline Mental retardasyon & 2 & 4 \\
\hline Aniridi & 1 & 2 \\
\hline Hemihipertrofi & 1 & 2 \\
\hline
\end{tabular}

Tablo 2: Hastaların patolojik özellikleri ve evreleri

\begin{tabular}{|c|c|c|}
\hline & $\begin{array}{l}\text { Primer cerrahi olan hastalar } \\
\qquad(\mathrm{n}=27)\end{array}$ & $\begin{array}{c}\text { Preoperatif tedavi alan } \\
\text { hastalar } \\
\text { (n: } 22)\end{array}$ \\
\hline Wilms tümörü & $25(\% 92,6)$ & $19(\% 86,4)$ \\
\hline Mezoblastik nefroma & $2(\% 7,4)$ & 0 \\
\hline Böbreğin clear hücreli karsinomu & 0 & $2(\% 9,1)$ \\
\hline Böbreğin sinovyal sarkomu & 0 & $1(\% 4,5)$ \\
\hline \multicolumn{3}{|l|}{ Anaplazi } \\
\hline Fokal anaplazi & $2(\% 7,4)$ & $1(\% 4,5)$ \\
\hline Diffüz anaplazi & $2(\% 7,4)$ & $1(\% 4,5)$ \\
\hline \multicolumn{3}{|l|}{ SIOP'a göre risk grubu* } \\
\hline Düşük risk grubu & $2(\% 7,4)$ & $2(\% 9,1)$ \\
\hline Orta risk grubu & $24(\% 88,9)$ & $11(\% 50)$ \\
\hline Yüksek risk grubu & $1(\% 3,7)$ & $8(\% 36,4)$ \\
\hline \multicolumn{3}{|l|}{ Evre } \\
\hline Evre I & $14(\% 51,9)$ & $3(\% 13,6)$ \\
\hline Evre II & $10(\% 37)$ & $3(\% 13,6)$ \\
\hline Evre III & $2(\% 7,4)$ & $10(\% 45,5)$ \\
\hline Evre IV & $1(\% 3,7)$ & $4(518,2)$ \\
\hline Evre $\mathrm{V}$ & 0 & $2(\% 9,1)$ \\
\hline
\end{tabular}

SIOP: International Society of Paediatric Oncology

Preoperatif tedavi alan ve patolojisi böbreğin primer sinovyal sarkomu olan hastanın SIOP'a göre risk grubu tanımlanmamıştır.

Çocuklarda primer böbrek tümörü - Kara ve ark.

Tablo 3: Genel yaşam üzerine etki eden faktörler

\begin{tabular}{lcc}
\hline & Genel Yaşam Oranı & $p$ \\
& $(\%)$ & 0,39 \\
\hline Cinsiyet & 72 & \\
Erkek & 83,5 & 0,68 \\
Kız & \\
İlk tedavi yaklaşımı & 77 & \\
Primer cerrahi uygulananlar & 80,4 \\
Preoperatif tedavi uygulananlar & \\
Evre & 91 \\
I & 60 \\
II & 77 \\
III & 75
\end{tabular}

Hasta yaygınllğı

0,9

Lokalize hastalık, (evre I ve II) $\quad 82,5$

Yaygın hastalık, (evre III ve IV)

78

Anaplazi

0,53

Yok 82

Fokal 66,7

Diffüz $\quad 66,7$

$\begin{array}{ll}\text { SIOP risk grubuna göre } & 0,76\end{array}$

Düșük risk 100

Orta risk 78

Yüksek risk 75

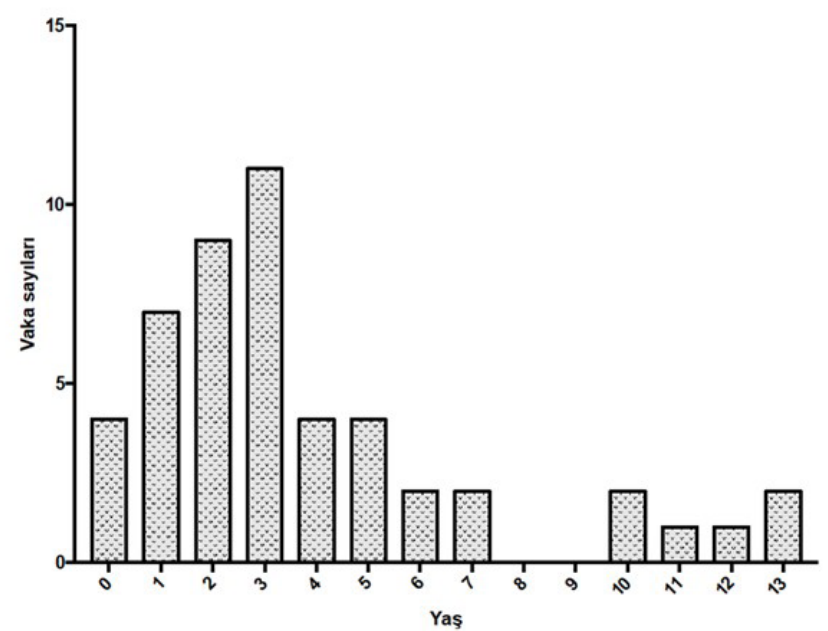

Resim 1: Hastaların yaşlara göre dağılımı 


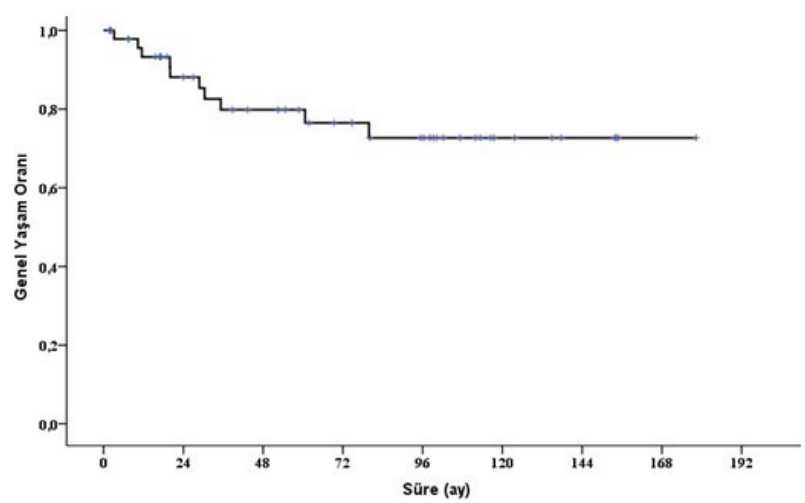

Resim 2: Tüm hastaların genel yaşam oranı

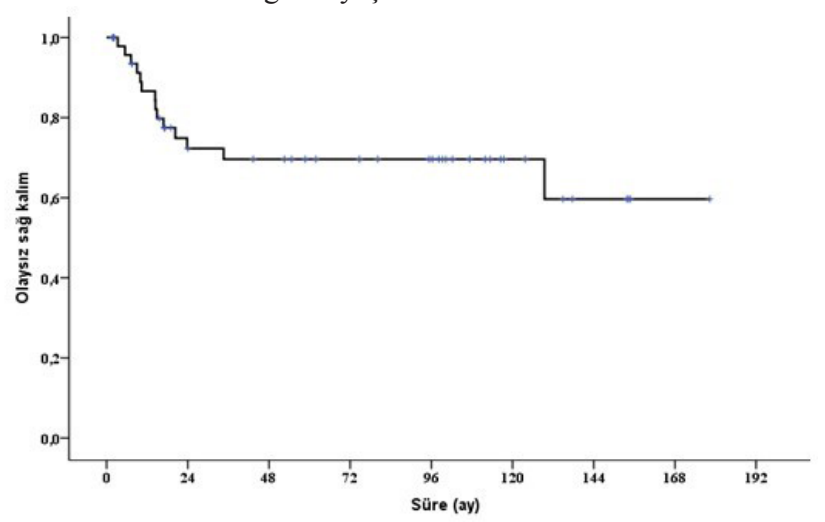

Resim 3: Tüm hastaların olaysız yaşam oranı

\section{Tartıșma}

Çocuklarda, primer malign böbrek tümörleri, merkezlere göre küçük farklılıklar olsa da tüm çocukluk çağı malign hastalıklarının yaklaşık \%6'sını oluşturur ve çocukluk çağının en yaygın beşinci malign tümörüdür $(1-3,10)$. Çocukluk çağındaki primer malign böbrek tümörlerinin tamamına yakınını embriyonik bir tümör olan Wilms tümörü oluşturmaktadır. Bu çalışmada, kliniğimizde primer malign böbrek tümörü tanısı alan ve izlenen hastaların, demografik ve klinik özellikleri, tedavi yaklaşımları, tedavi sonuçları ve tedavi sonuçları üzerine etki eden faktörler araştırılmıştır.

Wilms tümörü ya da mezoblastik nefroma genellikle yaşamın ilk beş yaşında görülürken, renal hücreli karsinom, böbreğin rabdoid tümörü ve böbreğin clear hücreli karsinomu gibi diğer pediatrik primer malign böbrek tümörleri genellikle onlu yaşlarda görülmektedir (3, 10). Bizim çalışmamızda da benzer şekilde, hastaların yaşları üç gün ile 13 yıl arasında değişmekte olup ve tümörlerin önemli bir kısmı yaşamın ilk yıllarında ortaya çıkmaktadır.

Primer malign böbrek tümörlü hastalarda, başvuru yakınması genellikle anne tarafindan giydirilirken ya da banyo yaptırılırken veya rutin doktor kontrolü sırasında saptanan karında şşşlik yakınmasıdır. Bunun dışında karın ağrısı, hematüri, ateş, halsizlik, iştahsızlık ve kilo kaybı gibi yakınmalar da olabilir. Fizik muayenede ise en s1k karında kitle saptanır. Daha az oranda hipertansiyon, konjenital malformasyonlar var ise ona ait bulgular ve varikosel diğer bulgulardır (3). Bizim hastalarımızda en sık başvuru yakınması ve fizik muayene bulgusu karında kitle idi $(\mathrm{n}=27, \% 55,1)$. Hastalarımızda, saptanan konjenital malformasyonlar ise iki hastada vard 1 ve bunlar WAGR sendromu ile Beckwith-Wiedemann sendromuydu.
Primer malign böbrek tümörlerinde büyük bir kısmını Wilms tümörü oluşturduğu için evrelendirmede genellikle ya SIOP'un evrelendirme sistemi ya da NWTS grubunun evrelendirme sistemi kullanılmaktadır. Ancak, bizim çalışmamızda hastaların önemli bir kısmı Türk Pediatrik Onkoloji Grubunun Wilms tümörü çalışması sırasında olduğu için genellikle bu evrelendirme sistemi kullanıldı. Gerek NWTS, gerek SIOP gerekse Türk Pediatrik Onkoloji Grubunun Wilms tümörü çalışmasında kullanılan evrelendirme sistemlerinde ciddi farkl11ıklar yoktur. Türk Pediatrik Onkoloji Grubunun Wilms tümörü çalışmasında hasta evrelerinin büyük bir kısmını Evre I $(\% 23,6)$ ve IIA $(\% 36,4)$ oluşturmaktadır $(7)$ Bizim tüm hastalarımız dikkate alındığında, en çok evre I ve III'de olduğu görülmektedir. İki hastamızda tanı anında bilateral hastalık vardı ve evre V'di.

Wilms tümörlü hastalarda prognoz üzerine etkili olan faktörlerden birisi de evre ile beraber kötü histoloji grubuna sahip olmasıdır. İyi ya da kötü histoloji grubu tanımlanmasında en temel faktörlerin başında yaygın anaplazinin varlığıdır $(3,10)$. SIOP sınıflandırmasına göre hastalar preoperatif tedavi alıp almamasına göre iki ana gruba ayrılmaktadır. Preoperatif tedavi almayan hastalarda, yaygın anaplazi görülen Wilms tümörü, böbreğin clear hücreli sarkomu, Rabdoid tümör, preoperatif tedavi alan hastalarda ise blastemal tip Wilms tümörü yüksek risk grubunda yer almaktadır (8). Wilms tümörlü hastalarda prognoz üzerine etkili olan faktörlerden birisi de evre ile beraber kötü histoloji grubuna sahip olmasıdır. İyi ya da kötü histoloji grubu tanımlanmasında en temel faktörlerin başında yaygın anaplazinin varlığıdır $(3,10)$.Bizim üç hastamızda diffüz anaplazi, üç hastamızda ise fokal anaplazi saptandı. International Society of Paediatric Oncology'un önerdiği patolojik risk grupları dikkate alındığında hastalarımızı iyi, orta ve kötü risk grubu oranları değerlendirildiğinde en çok orta risk grubunda olduğu görülmekteydi.

Wilms tümörlerinde prognoz üzerinde etkili faktörler; evre ve anaplazi veya histolojik gruptur. İyi histoloji grubunda, Evre I'den IV'e kadar beklenen genel sağ kalım oranları \%99'den \%85'e kadar değişiyorken; diffüz anaplazi varlığında bu oranlar \%82'den \%33'e kadar değişmektedir (10). Ülkemizde Türk Pediatrik Onkoloji grubunun çalışmasının sonuçlarına göre; erken evrelerde genel sağkalım oranları \%90'ların üzerindeyken bu oran evre IV'de yaklaşık olarak \%34'tür. İyi histoloji grubunda \%95 olan genel sağkalım oranı kötü histoloji grubunda \%70'tir (7). Hacettepe Üniversitesi Pediatrik Onkoloji Bilim Dalı'nda yapılan ve 1972 ile 1999 yılları arasında Wilms tümörü tanısı alanların incelendiği geniş kapsamlı çalışmada, yıllar içinde genel sağ kalım oranlarının arttığı görülmüştür (11). Ülkemizde yapılan diğer çalışmalarda da benzer şekilde Wilms tümörünün genel sağ kalım oranlarının giderek arttığı görülmektedir $(12,13)$. Bizim çalışmamızda tüm hastaların genel ve hastalıksız sağ kalım oranları sırasıyla \% 72,7 ve \% 59,7 idi. Ancak analize sadece Wilms tümörleri dâhil edildiğinde bu oranlar \%79 ve $\% 63$ 'dü. Bu oranlar diğer çalışmalar ile uyumluydu. ilginç olarak, cinsiyet, ilk tedavi yaklaşımı, Evre, hastalık yaygınlığı, anaplazi varlığı ve SIOP'a göre risk sınıflandırmasının genel yaşam analizleri üzerine etki etmediği görüldü. Bunun sebebi, genel hasta sayımızın ve bazı alt gruplara düşen hasta sayımızın az olması olabilir.

\section{Sonuç}

Çocuklarda primer böbrek tümörü - Kara ve ark. 
Primer malign böbrek tümörlerinde ve özellikle de Wilms tümöründe multidisipliner yaklaşım ile genel sağ kalım oranlarında yüz güldürücü sonuçlar elde edilmiştir ve bundan sonra tedavinın daha başarılı olması ve tedavi ilişkili yan etkilerin azaltılması üzerinde durulmalıdır.

\section{Teşekkürler}

Selçuk Üniversitesi, Tıp Fakültesinde yıllarca kanserli çocukların tanı, tedavi ve takibinde emeği geçen tüm tıp doktorlarına ve sağlık ekibine teşekkür ederiz.

\section{Kaynaklar}

1.Kutluk T, Yesilipek MA. Turkish national pediatric cancer registry 2002-2008 (Turkish Pediatric Oncology Group and Turkish Pediatric Hematology Society). Pediatr Blood Cancer. 2009; 53: 851.

2.Kutluk T, Sahiner UM, Akyuz C, et al. A hospital based pediatric cancer registry, Hacettepe experience 1971-2004. Pediatr Blood Cancer. 2009; 53: 851.

3.Varan A. Wilms' tumor in children: an overview. Nephron Clin Pract. 2008; 108: c8390 .

4.Bozlu G, Çıtak EÇ. Evaluation of renal tumors in children. Turk J Urol. 2018; 44: 268 73.

5.Qureshi SS, Bhagat M, Verma K, et al. Incidence, treatment, and outcomes of primary and recurrent Non-Wilms renal tumors in children: Report of 109 patients treated at a single institution. J Pediatr Urol. 2020;16: 475.e1-475.e9.

6.Varan A, Kalkan N, Yalcin B, et al. Wilms tumor associated with genetic syndromes and congenital malformations. Eur J Pediatr 2017; 176: 1451.

7.Akyüz C, Yalçin B, Yildiz I, et al. Treatment of Wilms tumor: a report from the Turkish Pediatric Oncology Group (TPOG). Pediatr Hematol Oncol. 2010; 27: 161-78.

8.Vujanić GM, Sandstedt B, Harms D, Kelsey A, Leuschner I, de Kraker J; SIOP Nephroblastoma Scientific Committee. Revised International Society of Paediatric Oncology (SIOP) working classification of renal tumors of childhood. Med Pediatr Oncol. 2002; 38: 79-82.

9.Graf N, van Tinteren H, Bergeron C, et al. Characteristics and outcome of stage II and III non-anaplastic Wilms' tumour treated according to the SIOP trial and study 93-01. Eur J Cancer. 2012; 48(17): 3240-8.

10.Warwick AB, Dome JS. Renal Tumors. In: Lanzkowsky P, Lipton JM and Fish JD, eds. Lanzkowsky's Manual of Pediatric Hematology and Oncology. 6th ed. Amsterdam: Elsevier, 2016; 491-504.

11.Kutluk T, Varan A, Büyükpamukçu N, et al. Improved survival of children with Wilms tumor. J Pediatr Hematol Oncol. 2006; 28: 423-6.

12.Yildiz I, Yüksel L, Ozkan A, et al. Multidisciplinary approach to Wilms' tumor: 18 years of experience. Jpn J Clin Oncol. 2000; 30: 17-20.

13.Erginel B, Vural S, Akın M, et al. Wilms' tumor: a 24-year retrospective study from a single center. Pediatr Hematol Oncol. 2014; 31: 409-14. 